\title{
FORMULASI SEDIAAN GEL EKSTRAK ETANOL 96\% RIMPANG JAHE MERAH (Zingiber officinale Rosc. Var. Rubrum) DENGAN HIDROKSIETIL SELULOSA SEBAGAI GELLING AGENT
}

\author{
Pricillya M L ${ }^{1}$, Senny Listy K F ${ }^{2,}$ Siska Julisna ${ }^{3}$ \\ ${ }^{1,2,3}$ Akademi Farmasi IKIFA \\ Email Korespondensi : sennylisty@yahoo.com
}

\begin{abstract}
ABSTRAK
Jahe merah (Zingiber officinale Rosc. Var. Rubrum) adalah tanaman yang telah banyak diteliti memiliki aktivitas antibakteri terhadap Propionibacterium acnes yang merupakan salah satu penyebab jerawat. Salah satu bentuk sediaan topikal yang sering digunakan untuk pengobatan jerawat adalah bentuk sediaan gel. Dalam formulasi gel ekstrak etanol 96\% rimpang jahe merah ini digunakan Hidroksietil Selulosa sebagai gelling agent. Penelitian ini bertujuan untuk mengetahui pengaruh peningkatan konsentrasi Hidroksietil Selulosa terhadap formulasi sediaan gel ekstrak etanol $96 \%$ rimpang jahe merah. Gel dibuat menjadi 3 formula dengan konsentrasi masing-masing $2 \%, 2.5 \%$, dan $3 \%$. Tiap formula kemudian diuji sifat organaleptis, homogenitas, $\mathrm{pH}$ dan viskositas. Hasil penelitian menunjukkan sediaan pada uji organoleptis tidak mengalami perubahan, homogen dan $\mathrm{pH}$ stabil. Dari hasil perubahan viskositas formula 1, 2 dan 3 mengalami peningkatan seiring dengan bertambahnya waktu penyimpanan, viskositas yang paling kecil ada pada formula 1 dengan konsentrasi gelling agent $2 \%$. Berdasarkan penelitian yang dilakukan dapat disimpulkan bahwa formula 1 Hidroksietil selulosa dengan konsentrasi $2 \%$ sebagai gelling agent yang paling baik berdasarkan mutu fisik, kimia dan uji organoleptis sediaan.
\end{abstract}

Kata kunci : Formulasi, Ekstrak Etanol 96\% Rimpang Jahe Merah, Gel, Hidroksietil selulosa 


\section{ABSTRACT}

Zingiber officinale Rosc. Var. Rubrum is a plant that has been determined to have antibacteria activity for Propionibacterium acnes which serve as one of the cause of acnes. Gel is the topical form used to acne's medication. Hydroxiethyl Cellulose is used as gelling agent in gel of red ginger's root's ethanol $96 \%$ extract. The goal of the research is to determine the influence of increased concentration of hydroxiethyl cellulose to the formulation of red ginger's root's extract of ethanol 96\%. The gel was made into 3 formulas with each concentration of 2\%, 2.5\%, and 3\%. Each formulas wastested about the organoleptics, homogenity, $\mathrm{pH}$, and viscosity. The result shows that on organoleptic test, the gels don't have any change, they are homogen and their $\mathrm{pH}$ were stable. Based on the viscosity test, 1st, 2nd and $3 r$ formulas have some increase with the addition of storage's time. The formula 1 have less viscocity with the concentration of about $2 \%$. Based on this research, we can conclude that the 1 st formula was the best one based on the physical, chemical quality and the organoleptic test.

Keywords : Formulation, Red Ginger's Root's Extract of Ethanol 96\%, Hydroxiethyl cellulose

\section{PENDAHULUAN}

Jahe merah (Zingiber officinale Rosc. Var. Rubrum) merupakan tanaman yang telah banyak diteliti memiliki aktivitas antibakteri. Kandungan senyawa yang terdapat pada jahe merah dapat memberikan aktivitas antibakteri diantaranya flavonoid, fenol, minyak atsiri, triterpenoid dan tanin (Fissy, 2014). Hal ini yang menyebabkan jahe merah lebih sering digunakan dalam dunia pengobatan.

Selain itu, ekstrak jahe merah memberikan aktivitas antibakteri terhadap bakteri Gram positif seperti $S$. epidermis, S.aureus, S. agalactiae, Listeria monocytogenes dan Propionibacterium acnes (Fissy, 2014), sehingga dapat diasumsi bahwa ekstrak rimpang jahe merah juga dapat memberikan aktivitas yang sama terhadap bakteri Gram positif penyebab jerawat yaitu P.acne dan P.epidermis.

Banyaknya penelitian mengenai aktivitas antibakteri dari ekstrak rimpang jahe merah (Zingiber officinale Rosc.
Var. Rubrum) dan besarnya risiko serta jumlah penderita jerawat mendorong untuk memformulasikan sediaan gel dari ekstrak rimpang jahe merah (Zingiber officinale Rosc. Var.rubrum) sebagai obat anti jerawat. Berdasarkan penelitian sebelumnya menunjukkan bahwa $0,5 \%$ ekstrak rimpang jahe merah berkhasiat sebagai anti jerawat (Fissy, 2014).

Pada permukaan kulit manusia terdapat berbagai mikroorganisme yang pada kondisi tertentu mikroorganisme tersebut mampu menginfeksi kulit. Staphylococcus aureus dan Pseudomonas aeruginosa diketahui sebagai infeksi kulit dan jaringan lunak yang mampu mengancam jiwa. Kulit merupakan organ terluas penyusun tubuh manusia yang terletak paling luar dan menutupi seluruh permukaan tubuh. Letak paling luar menyebabkan kulit pertama kali menerima rangsangan sentuhan, rasa sakit, maupun pengaruh buruk dari luar. Hal-hal tersebut menyebabkan kulit rentan terkena penyakit. Salah satu penyakit kulit yang 
paling sering diderita oleh masyarakat adalah jerawat (Wiguna, 2016).

Secara alamiah kulit telah berusaha untuk melindungi diri dari serangan mikroorganisme dengan adanya tabir lemak diatas kulit yang diperoleh dari kelenjar lemak dan sedikit kelenjar keringat dari kulit serta adanya lapisan kulit luar yang berfungsi sebagai sawar kulit. Namun dalam kondisi tertentu faktor perlindungan alamiah tersebut tidak mencukupi dan sering kali akibat bakteri yang melekat pada kulit menyebabkan jerawat (Wiguna, 2016).

Jerawat (acne) adalah salah satu penyakit kulit yang selalu mendapat perhatian bagi para remaja dan dewasa muda. Kulit yang berminyak menyebabkan pori-pori tersumbat, sehingga bakteri anaerobik seperti Staphylococcus akan berkembangbiak dengan cepat dan menyebabkan timbulnya jerawat. Oleh karena itu di butuhkan kosmetika untuk mengobati jerawat agar bakteri penyebab jerawat tersebut dapat dihilangkan (Wiguna, 2016).

Bentuk sediaan gel lebih baik digunakan pada pengobatan jerawat daripada bentuk krim karena sediaan gel dengan pelarut polar lebih mudah dibersihkan dari permukaan kulit setelah pemakain dan tidak mengandung minyak yang dapat meningkatkan keparahan jerawat. Gel dipilih karena tidak mengandung minyak sehingga tidak akan memperburuk jerawat, bening, mudah mengering membentuk lapisan film yang mudah dicuci, juga bentuk sediaan gel cocok untuk terapi topikal pada jerawat terutama penderita dengan tipe kulit berminyak (Wiguna, 2016).

Turunan selulosa merupakan basis pembentuk gel yang paling banyak digunakan karena menghasilkan gel yang netral, memiliki daya tahan terhadap serangan mikroba, dan mempunyai kejernihan yang tinggi. Hidroksietil selulosa merupakan turunan selulosa yang dapat larut dalam air panas dan air dingin (Voigt, 1994).

Berdasarkan latar belakang di atas, maka penulis ingin melakukan penelitian mengenai formulasi sediaan gel ekstrak etanol $96 \%$ rimpang jahe merah (Zingiber officinale Rosc. Var. Rubrum) dengan Hidroksietil selulosa sebagai gelling agent.

\section{METODE PENELITIAN}

\section{Pembuatan ekstrak rimpang jahe merah}

Rimpang jahe merah yang terkumpul dibersihkan dari kotoran yang menempel. Rimpang yang telah bersih kemudian di kupas dan dirajang.

Pembuatan ekstrak rimpang jahe merah dilakukan dengan cara sokletasi. Serbuk simplisia rimpang jahe merah di timbang $25 \mathrm{~g}$ dan di masukkan ke dalam wadah sampel, dimasukkan 500ml etanol 96\% ke dalam labu lalu di panaskan sampai mendidih dan menguap, ekstrak etanol $96 \%$ jahe merah dikentalkan menggunakan vacum rotary evaporator, di timbang berat ekstraknya dan dihitung rendemennya (Putri, 2014).

\section{Identifikasi senyawa}

\section{a. Uji flavonoid}

Sebanyak 0,5 gram ekstrak kental ditambahkan 2 tetes larutan $\mathrm{NaOH}$. Terbentuknya warna kuning 
yang menjadi tidak berwarna dengan penambahan asam encer menunjukkan adanya flavonoid (Fathurrachman, 2014).

b. Uji terpenoid

Sebanyak 0,5 gram ekstrak kental ditambahkan kloroform dan reagen Lieberman Burchard. Kemudian larutan dikocok perlahan dan di biarkan selama beberapa menit. Triterpenoid akan memberikan warna merah atau ungu (Putri, 2014).

Tabel 1. Formulasi Gel

\begin{tabular}{|c|c|c|c|c|}
\hline \multirow[t]{2}{*}{ Bahan } & \multicolumn{3}{|c|}{ Formula \% } & \multirow{2}{*}{$\begin{array}{c}\text { Kegun } \\
\text { aan }\end{array}$} \\
\hline & F1 & F2 & F3 & \\
\hline $\begin{array}{c}\text { Ekstrak } \\
\text { etanol } \\
96 \% \\
\text { rimpang } \\
\text { jahe } \\
\text { merah }\end{array}$ & 0,5 & 0,5 & 0,5 & $\begin{array}{l}\text { Zat } \\
\text { aktif }\end{array}$ \\
\hline $\begin{array}{l}\text { Hidroksiet } \\
\text { il selulosa }\end{array}$ & 2 & 2,5 & 3 & $\begin{array}{c}\text { Basis } \\
\text { gel }\end{array}$ \\
\hline Gliserin & 15 & 15 & 15 & $\begin{array}{c}\text { Humect } \\
\text { an }\end{array}$ \\
\hline $\begin{array}{c}\text { Metil } \\
\text { paraben }\end{array}$ & 0,18 & 0,18 & 0,18 & $\begin{array}{c}\text { Pengaw } \\
\text { et }\end{array}$ \\
\hline $\begin{array}{c}\text { Propil } \\
\text { paraben }\end{array}$ & 0,02 & 0,02 & 0,02 & $\begin{array}{c}\text { Pengaw } \\
\text { et }\end{array}$ \\
\hline Aqua dest & 100 & 100 & 100 & Pelarut \\
\hline
\end{tabular}

c. Evaluasi sediaan gel

Evaluasi sediaan gel dilakukan pada suhu kamar diamati secara berkala pada minggu ke $0,1,2,3$, dan 4

1) Organoleptis

Diamati warna, bau dan bentuk gel (Yulin, 2015).

a) Warna : pengamatan warna dilakukan secara visual dengan mata terhadap gel yang dikemas dalam botol bening.

b) Bau : bau dari gel yang telah disimpan dalam wadah yang sesuai dilakukan dengan cara membuka tutup botol dari sediaan dan dicium aromanya.

c) Bentuk : diamati secara visual dengan mata

2) Homogenitas

Uji homogenitas dilakukan dengan meletakkan sediaan diatas kaca objek, lalu di perhatikan adanya partikel-partikel kasar atau ketidak homogenan di bawah cahaya (Yulin, 2015).

3) Pengukuran $\mathrm{pH}$

Pengukuran $\mathrm{pH}$ larutan gel menggunakan $\mathrm{pH}$ meter dengan prosedur sebagai berikut (Yulin, 2015) :

a) Cuci dan bilas elektroda dengan aquadest.

b) Kalibrasi $\mathrm{pH}$ meter dengan larutan dapar $\mathrm{pH} 4$ dan 7.

c) Siapkan gel yang akan diukur.

d) Celupkan elektroda $\mathrm{pH}$ yang telah dibersihkan sedemikian rupa sampai ujung elektroda tercelup ke dalam sediaan

e) Catat $\mathrm{pH}$ yang didapat, pengukuran dilakukan 3 kali.

4) Viskositas

Sediaan gel dimasukkan ke dalam gelas. Pemeriksaan dilakukan dengan menggunakan viskometer Brookfield 
dengan menggunakan spindel yang sesuai, kemudian dimasukkan ke dalam sediaan sampai tanda batas yang ada pada spindel s64 (Setyaningrum, 2013)

\section{HASIL DAN PEMBAHASAN}

Karakteristik Ekstrak Etanol 96\%

Rimpang Jahe Merah

Tabel 2. Karakteristik Ekstrak Etanol 96\% Rimpang Jahe Merah

\begin{tabular}{cc}
\hline Karakteristik & Hasil pengamatan \\
\hline Bentuk & Kental \\
Bau & Khas aroma jahe merah \\
Warna & Coklat kekuningan \\
Rendemen & $5,3847 \% \mathrm{~b} / \mathrm{b}$ \\
\hline
\end{tabular}

Hasil Identifikasi Ekstrak Etanol 96\% Rimpang Jahe Merah

Hasil identifikasi pada ekstrak etanol 96\% rimpang jahe merah dapat dilihat pada tabel 4.2.

Tabel 3. Hasil Identifikasi

\begin{tabular}{ccc}
\hline No & Kandungan & Hasil \\
\hline $\mathbf{1}$ & Flavonoid & + \\
$\mathbf{2}$ & Terpenoid & + \\
\hline
\end{tabular}

Ket : $+=$ mengandung zat aktif

- = tidak mengandung zat aktif

\section{Orientasi Hidroksi Selulosa Sebagai Gelling Agent}

Sebelum pembuatan formula gel, dilakukan orientasi konsentrasi gelling agent terlebih dahulu, hasil orientasi sebagai berikut:

Tabel 4. Hasil Orientasi Hidroksietil Selulosa

\begin{tabular}{cc}
\hline Orientasi & Hasil \\
\hline $\mathbf{4 \%}$ & Tidak bisa mengalir \\
& menjadi padat \\
$\mathbf{3 , 5 \%}$ & Tidak bisa mengalir \\
& menjadi padat \\
& Menghasilkan kental \\
$\mathbf{3 \%}$ & berbentuk gel \\
& Kental berbentuk gel \\
$\mathbf{2 , 5 \%}$ & Kental berbentuk gel \\
\hline
\end{tabular}

Evaluasi Sediaan Gel

Pengamatan Organoleptis dan

Homogenitas

Pengamatan organoleptis dan homogenitas dilakukan dengan mengamati bentuk, warna, bau dan homogenitas yang terjadi selama 4 minggu. Pemeriksaan sediaan awal memberikan hasil dengan bentuk gel, warna bening kekuningan, bau khas jahe merah dan homogen, seperti pada tabel 5

Tabel 5. Organoleptis dan Homogenitas Gel Ekstrak Etanol 96\% Rimpang Jahe Merah

\begin{tabular}{ccccccc}
\hline Formula & Pengujian organoleptis & \multicolumn{5}{c}{ Waktu (minggu) } \\
\cline { 3 - 7 } 1 & & $\mathbf{0}$ & $\mathbf{1}$ & $\mathbf{2}$ & $\mathbf{3}$ & $\mathbf{4}$ \\
& Warna & +++ & +++ & +++ & +++ & +++ \\
& Bau & +++ & +++ & +++ & +++ & +++ \\
& Bentuk & +++ & +++ & +++ & +++ & +++ \\
2 & Homogenitas & +++ & +++ & +++ & +++ & +++ \\
& Warna & +++ & +++ & +++ & +++ & +++ \\
& Bau & +++ & +++ & +++ & +++ & +++ \\
& Bentuk & +++ & +++ & +++ & +++ & +++ \\
\hline
\end{tabular}




\begin{tabular}{ccccccc}
\hline & Homogenitas & +++ & +++ & +++ & +++ & +++ \\
Warna & +++ & +++ & +++ & +++ & +++ \\
Bau & +++ & +++ & +++ & +++ & +++ \\
& Bentuk & +++ & +++ & +++ & +++ & +++ \\
& Homogenitas & +++ & +++ & +++ & +++ & +++ \\
\hline
\end{tabular}

Keterangan $:(+++)=$ tidak terjadi perubahan

$(++)=$ sedikit terjadi perubahan

$(+)=$ terjadi perubahan

Uji organoleptis dilakukan secara visual dengan mengamati ada tidaknya perubahan warna, bau dan bentuk sediaan gel selama penyimpanan. Sedangkan uji homogenitas dilakukan dengan cara mengoleskan sediaan gel secara tipis-tipis pada kaca objek, kemudian ditutup dengan kaca objek, dan diamati dibawah cahaya apakah terdapat partikel-partikel kasar atau ketidak homogenan. Dari hasil pengamatan gel selama 4 minggu tidak mengalami perubahan apapun, hal ini menunjukkan bahwa ke-3 formula stabil secara fisik.

\section{Pengukuran pH}

Nilai $\mathrm{pH}$ adalah derajat keasaman yang digunakan untuk menyatakan tingkat keasaman atau kebasaan yang dimiliki oleh suatu sediaan. Pengukuran $\mathrm{pH}$ dalam penelitian ini dilakukan dengan menggunakan $\mathrm{pH}$ meter.

Berdasarkan grafik dapat dilihat bahwa nilai $\mathrm{pH}$ mengalami penurunan selama waktu penyimpanan, namun masih memenuhi persyaratan $\mathrm{pH}$ kulit yaitu 4,5-7,0 sehingga sediaan aman digunakan (Wasitaatmadja, 1997) Penurunan nilai $\mathrm{pH}$ gel terjadi karena reaksi hidrolisis pada gugus hidroksietil $(\mathrm{OH})$ sehingga ion $\mathrm{H}^{+}$semakin banyak, sehingga semakin asam.

\section{Pengukuran Viskositas dan Sifat Alir}

Hasil pengukuran viskositas selama 4 minggu dapat dilihat pada grafik berikut:

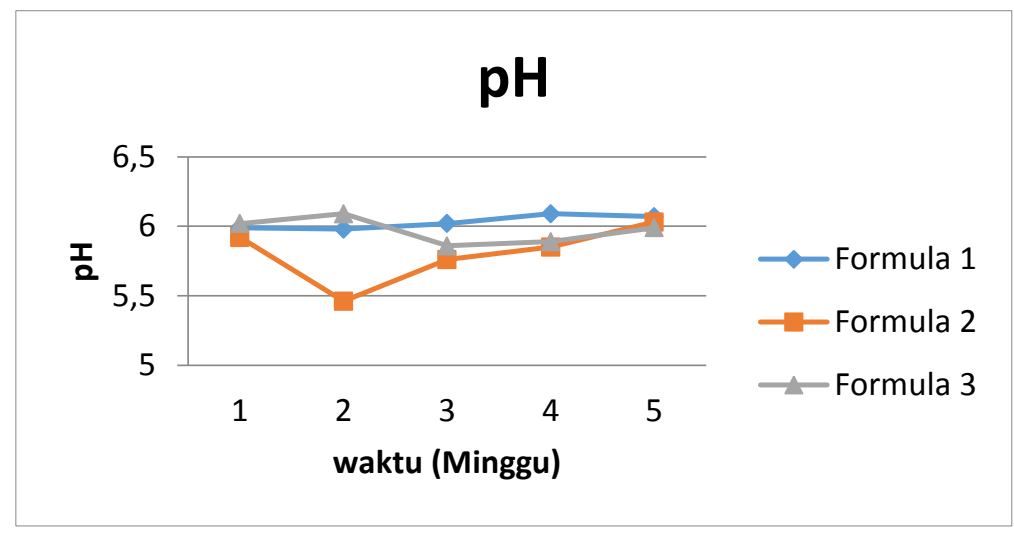

Gambar 1. Grafik Hasil Pengukuran pH 


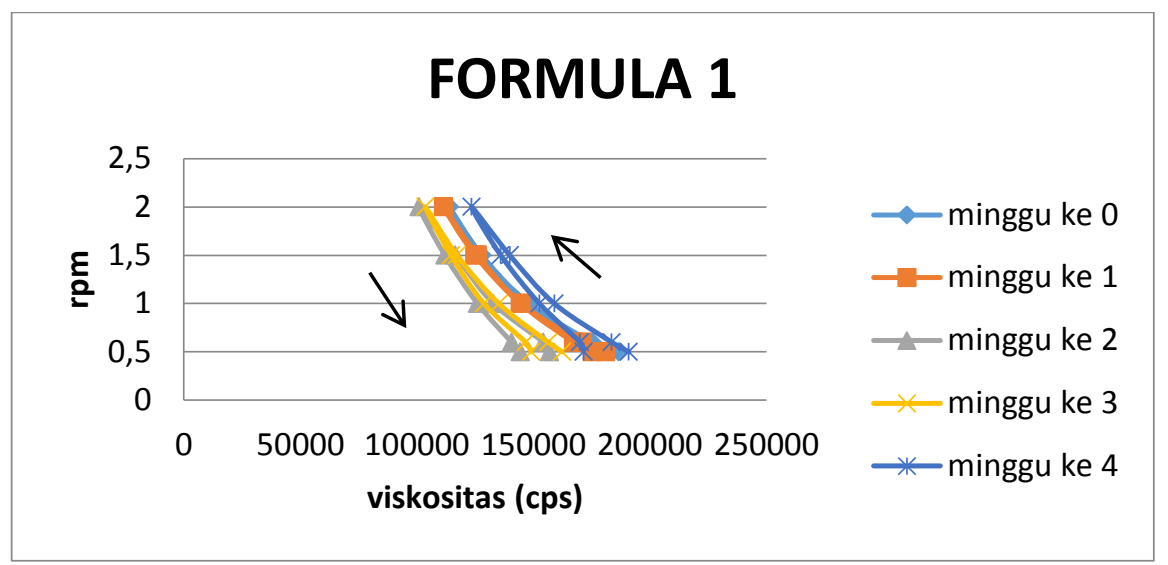

Gambar 2. Grafik Viskositas Formula 1

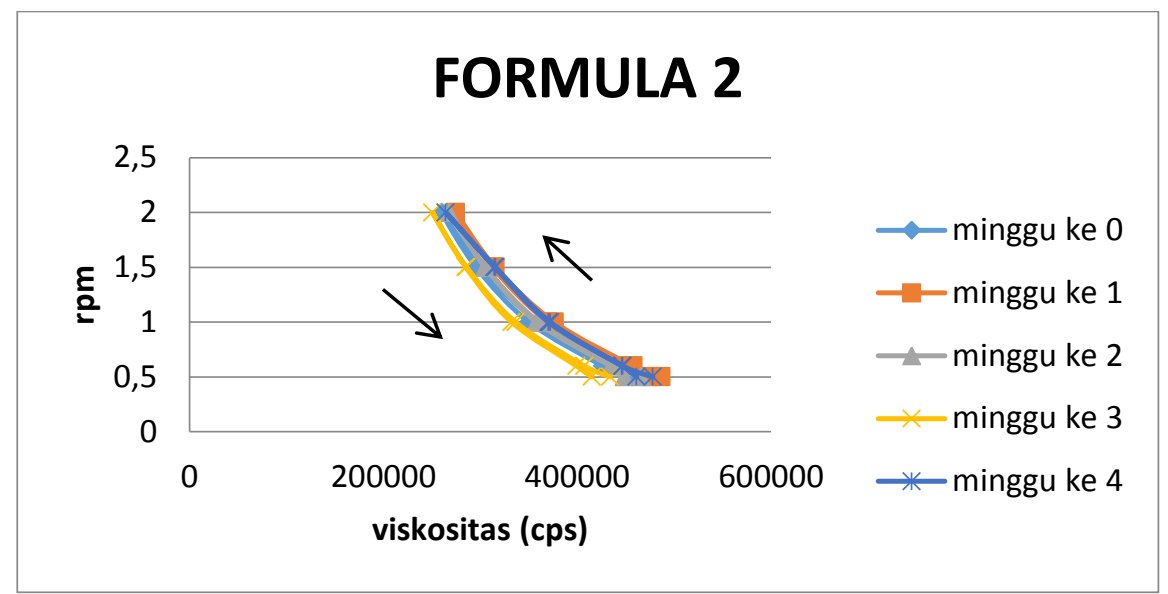

Gambar 3. Grafik Viskositas Formula 2

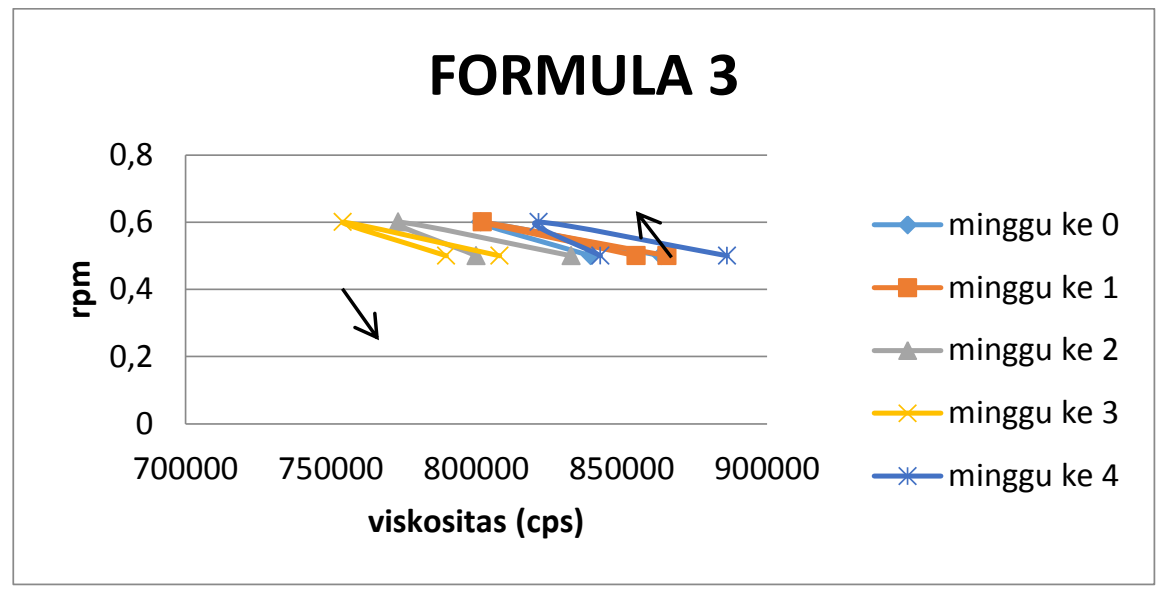

Gambar 4. Grafik Viskositas Formula 3

Pengukuran viskositas selama 4 minggu dengan menggunakan viskometer brookfield DV-E dengan spindel nomor s64 pada kecepatan 0,5-2 rpm. Berdasarkan grafik diatas menunjukkan ke-3 formula mengalami peningkatan viskositas seiring dengan bertambahnya waktu penyimpanan. Viskositas yang dihasilkan berbedabeda pada setiap formula.

Peningkatan viskositas kemungkinan terjadi karena proses pendiaman yang 
membuat gelling agent mengembang. Hidroksietil selulosa bekerja melalui proses pengembangan dengan cara mengikat air yang ada sehingga molekul-molekul air akan saling berdekatan dan terjadi gaya tarik menarik. Semakin tinggi konsentrasi hidroksietil selulosa maka akan semakin banyak ikatan antara fase pendispersinya dan terdispersinya sehingga konsentrasi sediaan menjadi lebih stabil. Hidroksietil selulosa stabil pada $\mathrm{pH}$ 5,5-8,5, maka jika $\mathrm{pH}$ sediaan kurang dari range tersebut sediaan tidak stabil dan otomatis akan mempengaruhi viskositas (Rowe, 2009).

Dari hasil yang didapat dari grafik dapat disimpulkan bahwa ke-3 formula gel memiliki sifat alir tiksotropik karena pada kurva terlihat adanya kurva turun disebelah kiri dari kurva naik, hal ini menunjukkan gel memiliki viskositas lebih rendah pada setiap kecepatan geser. Hal ini terjadi karena adanya pemecahan struktur yang tidak terbentuk kembali dengan segera jika stress tersebut dhilangkan atau dikurangi. Sifat alir tiksotropik merupakan sifat alir yang di harapkan dalam suatu sediaan gel dimana sediaan memiliki konsistensi tinggi dalam wadah, tetapi sedikit gaya yang dapat dikeluarkan dari wadah dengan mudah dan mudah menyebar jika digunakan pada kulit.

Hal ini menunjukkan bahwa sediaan memenuhi persyaratan gel yang baik karena memiliki sifat alir tiksotropik (Goeswin, 2012).

\section{SIMPULAN}

Berdasarkan dari hasil penelitian yang dilakukan dapat disimpulkan bahwa adanya pengaruh peningkatan konsentrasi Hidroksietil selulosa sebagai gelling agent terhadap formulasi sediaan gel ekstrak etanol 96\% rimpang jahe merah dan formulasi yang paling baik berdasarkan mutu fisik, kimia dan uji organoleptis sediaan adalah formula 1 dengan konsentrasi Hidroksietil selulosa $2 \%$ karena stabil dalam pengujian organoleptis dan homogenitas, pH nya 5,99 masih aman digunakan pada kulit, viskositasnya dari 186666,67-191000 cps dan sifat alirnya tiksotropik yang memiliki konsistensi tinggi dalam wadah dan mudah digunakan pada kulit.

\section{DAFTAR PUSTAKA}

Fathurrachman DA. Pengaruh Konsentrasi Pelarut Terhadap Aktivitas Antioksidan Ekstrak Etanol Daun Sirsak (Annona Muricata Linn) Dengan Metode Peredaman Radikal Bebas DPPH. Jakarta: Universitass Islam Negeri Syarif Hidayatullah; 2014, h 18.

Fissy ON, Sari R, Pratiwi R. Efektivitas Gel Anti Jerawat Ekstrak Etanol Rimpang Jahe Merah (Zingiber officinale Rosc. Var Rubrum) terhadap Propionibacterium acnes dan Staphylococcus epideemidis. Pontianak: Fakultas Kedokteran Universitas Tanjungpura; 2014, h 193-201.

Goeswin A. Sediaan Farmasi LikuidaSemisolida. Seri Farmasi Industri ke-7. ITB : Bandung; 2012, h 320. 
Putri DA. Pengaruh Metode Ekstraksi

Dan Konsentrasi Terhadap Aktivitas Jahe Merah (Zingiber Officinale Var Rubrum) Sebagai Anti Bakteri Escherichia Coli. Bengkulu: Universitas Bengkulu; 2014, h 25.

Rowe RC, Sheskey PJ, Quinn ME. Handbook of Pharmaceutical Excipients. 6th ed. Pharmaceutical Press And American Pharmacist Association. 2009, h 283, 311, 441, 596.

Setyaningrum NL. Pengaruh Variasi Kadar basis HPMC dalam Sediaan Gel Ekstrak Etanolik Bunga Kembang Sepatu (Hibiscus rosa sinensis L) Terhadap Sifat Fisik dan Daya Antibakteri Pada Staphylococcus aureus. Surakarta: Universitas Muhammadiyah Surakarta. 2013, h 7.

Voigt R. Buku Pelajaran Teknologi Farmasi. Terjemahan: Soendani
Noerono Soewandhi. Edisi ke-5. Gajah Mada. 1994. University Press, Yogyakarta, h 340-341.

Wasitaatmadja, SM, Penuntun Ilmu Kosmetik Medik. UI Press: Jakarta; 1997.

Wiguna A. Uji Aktivitas Formulasi Gel Anti Jerawat Ekstrak Daun Nangka (Artocarpus heterophyllus Lam) terhadap bakteri Staphylococcus aureus secara in vitro. Ciamis: Sekolah Tinggi Ilmu Kesehatan Muhammadiyah Ciamis; 2016, h 2.

Yulin HR. Uji Stabilitas Fisik Gel Masker Peel Off Serbuk Getah Buah Pepaya (Carica papaya L) dengan Basis Polivinil Alkohol dan Hidroksipropilmetil Selulosa. Jakarta: Universitas Islam Negeri Syarif Hidayatullah; 2015, h 28. 